\title{
RNA helical imperfections regulate activation of the protein kinase PKR: Effects of bulge position, size, and geometry
}

\author{
LAURIE A. HEINICKE, ${ }^{1,2}$ SUBBA RAO NALLAGATLA, ${ }^{1}$ CHELSEA M. HULL, and PHILIP C. BEVILACQUA \\ Department of Chemistry, Pennsylvania State University, University Park, Pennsylvania 16802, USA
}

\begin{abstract}
The protein kinase, PKR, is activated by long stretches of double-stranded (ds) RNA. Viruses often make long dsRNA elements with imperfections that still activate PKR. However, due to the complexity of the RNA structure, prediction of whether a given RNA is an activator of PKR is difficult. Herein, we systematically investigated how various RNA secondary structure defects contained within model dsRNA affect PKR activation. We find that bulges increasingly disfavor activation as they are moved toward the center of a duplex and as they are increased in size. Model RNAs designed to conform to cis, trans, or bent global geometries through strategic positioning of one or more bulges decreased activation of PKR relative to perfect dsRNA, although cis-bulged RNAs activated PKR much more potently than trans-bulged RNAs. Activation studies on bulge-containing chimeric duplexes support a model wherein PKR monomers interact adjacently, rather than through-space, for activation on bulged substrates. Last, unusually low ionic strength induced substantial increases in PKR activation in the presence of bulged RNAs suggesting that discrimination against bulges is higher under biological ionic strength conditions. Overall, this study provides a set of rules for understanding how secondary structural defects affect PKR activity.
\end{abstract}

Keywords: PKR; dsRNA; innate immunity

\section{INTRODUCTION}

PKR is a vital component of the innate immune response and has long been implicated in antiviral host defense mechanisms, where it is activated by long stretches of doublestranded RNA (dsRNA). Upon binding to long dsRNA, PKR undergoes dimerization and autophosphorylation and then phosphorylates its cellular substrate elongation initiation factor $2 \alpha$, and consequently translation is inhibited (Lemaire et al. 2005; Cole 2007). Activators of PKR include viral dsRNA replication intermediates from both DNA and RNA viruses, nonviral RNA aptamers, and a pseudoknot IFN- $\gamma$ mRNA promoter (Jacquemont and Roizman 1975; Katze et al. 1987; Maran and Mathews 1988; Bevilacqua et al. 1998;

\footnotetext{
${ }^{1}$ These authors contributed equally to this work.

${ }^{2}$ Present address: Department of Medicine, University of Pennsylvania School of Medicine, 437 Hill Pavilion, Philadelphia, PA 19104, USA.

Reprint requests to: Philip C. Bevilacqua, Department of Chemistry, Pennsylvania State University, University Park, PA 16802, USA; e-mail: pcb@chem.psu.edu; fax: (814) 865-2927.

Article published online ahead of print. Article and publication date are at http://www.rnajournal.org/cgi/doi/10.1261/rna.2636911.
}

Zheng and Bevilacqua 2004; Garcia et al. 2006). PKR interacts with these RNAs in a nonsequence specific fashion, and is regulated by RNAs containing helical defects, such as bulges, internal loops, stem-loops, multistem junctions, and even more complex tertiary interactions, such as pseudoknots and kissing hairpins (Zheng and Bevilacqua 2000; Ben-Asouli et al. 2002; Cohen-Chalamish et al. 2009; Heinicke et al. 2009). Due to the diversity of these RNA structural defects, it has been difficult to predict whether a given RNA structure will activate PKR.

We recently described PKR activation by HIV-1 TAR dimer, which contains multiple bulges (Heinicke et al. 2009). Numerous variants of TAR RNA were constructed to promote dimerization. On the basis of structure mapping and PKR activation results, we found that RNAs with more symmetrical defects were better activators. This observation provided motivation for the present study wherein we investigate how diverse bulges and internal loops affect PKR activation.

The conformation and flexibility of bulges and internal loops in helical RNA and DNA have been previously characterized by various methods, including native PAGE (Hsieh 
and Griffith 1989; Rice and Crothers 1989; Bhattacharyya et al. 1990; Tang and Draper 1990, 1994; Wang and Griffith 1991; Wang et al. 1991), transient electric birefringence (TEB) (Kebbekus et al. 1995; Zacharias and Hagerman 1995a; $\mathrm{Lu}$ et al. 2001), and ligase-catalyzed cyclization (Kahn et al. 1994). Electrophoretic mobility and TEB analyses indicate that bulges are not points of flexibility, but rather are rigid (Bhattacharyya et al. 1990; Tang and Draper 1994; Zacharias and Hagerman 1995a). Electrophoretic mobility data support this conclusion on the basis of pronounced retarded gel mobility with increasing bulge size, and less linear global geometry as seen with cis geometry of twobulge containing helices. Base identity also affects mobility, with more retarded mobility being associated with $A_{n}$ than $\mathrm{U}_{\mathrm{n}}$ bulges (Bhattacharyya et al. 1990; Zacharias and Hagerman 1995a). TEB analyses provide quantitative measurements for bend angles. Consistent with mobility measurements, $A_{n}$ bulges induce more acute bend angles than $\mathrm{U}_{\mathrm{n}}$ bulges. Moreover, the addition of bases opposite a bulge, to make an internal loop, reduces bending (Riordan et al. 1992).

The effect of salt on a bulge angle has also been examined. Addition of magnesium ions, which can compact the folds of certain RNA motifs, has little effect on $A_{n}$ bulge angles (Zacharias and Hagerman 1995a). However, laser light scattering experiments have revealed greater flexibility (i.e., decreased persistence length) of DNA in the presence of increased ionic strength from 5 to 200 to $1000 \mathrm{mM}$ $\mathrm{NaCl}$ (Kam et al. 1981).

Unlike bulged nucleic acids, internal loop-containing nucleic acids do not have pronounced changes in electrophoretic mobility, thus requiring a different methodological approach for study. The flexibility of internal loops in DNA has been examined by ligase-catalyzed cyclization experiments (Kahn et al. 1994). Using this approach, internal loops have been found to be quite flexible with no preference for bend orientation.

In the present study, we systematically examine how helical defect position, size, and geometry affect activation of PKR. We find that, in general, PKR activation is enhanced in the presence of less flexible and less bent RNA substrates.

\section{RESULTS}

\section{Sequence, geometry, and native gel mobility of bulged RNAs}

To investigate the effect of bulges and the role of RNA symmetry in PKR activation, we prepared a series of RNA duplexes containing symmetric or asymmetric adenosine bulges (see Table 1 for shorthand and a list of RNAs studied).
TABLE 1. Summary of RNA duplex constructs and nomenclature

\begin{tabular}{|c|c|c|c|c|}
\hline Construct name & LH-(center)-RH (bp) & Total bp & Total nt & Bulge size and strand \\
\hline dsRNA- $40^{\mathrm{a}}$ & $20-20$ & 40 & 80 & None \\
\hline bent $[2 \times 0]^{a}$ & $20-20$ & 40 & 82 & {$[2 \times 0] \mathrm{TS}$} \\
\hline flex $[2 \times 2]^{\mathrm{a}}$ & $20-20$ & 40 & 84 & {$[2 \times 2]$} \\
\hline dsRNA- $51^{b}$ & $20-11-20$ & 51 & 102 & None \\
\hline dsRNA-51-chi ${ }^{b, c}$ & $20-11(D)-20$ & 51 & 102 & None \\
\hline dsRNA-52 & 20-12-20 & 52 & 104 & None \\
\hline dsRNA- $53^{b}$ & $20-13-20$ & 53 & 106 & None \\
\hline $\operatorname{cis} 1^{\mathrm{d}}$ & $20-11-20$ & 51 & 104 & $2[1 \times 0] \mathrm{TS}$ \\
\hline $\operatorname{trans} 1^{\mathrm{d}}$ & $20-11-20$ & 51 & 104 & {$[1 \times 0] \mathrm{TS},[1 \times 0] \mathrm{BS}$} \\
\hline $\operatorname{cis} 1 \mathrm{~s}^{\mathrm{d}, \mathrm{e}}$ & $20-5-20$ & 45 & 92 & {$[1 \times 0]$ TS, $[1 \times 0]$ BS } \\
\hline trans $1 \mathrm{~s}^{\mathrm{d}, \mathrm{e}}$ & $20-5-20$ & 45 & 92 & $2[1 \times 0] \mathrm{TS}$ \\
\hline $\operatorname{cis} 2^{\mathrm{d}}$ & $20-11-20$ & 51 & 106 & $2[2 \times 0] \mathrm{TS}$ \\
\hline cis $2-$ chi $^{\mathrm{d}, \mathrm{c}}$ & $20-11$ (D)-20 & 51 & 106 & $2[2 \times 0]$ TS \\
\hline $\operatorname{trans} 2^{\mathrm{d}}$ & $20-11-20$ & 51 & 106 & {$[2 \times 0] \mathrm{TS},[2 \times 0] \mathrm{BS}$} \\
\hline bent $A^{d}$ & $46-5$ & 51 & 104 & {$[2 \times 0] \mathrm{BS}$} \\
\hline bent $B^{d}$ & $41-10$ & 51 & 104 & {$[2 \times 0] \mathrm{BS}$} \\
\hline bent $C^{d}$ & $36-15$ & 51 & 104 & {$[2 \times 0] \mathrm{BS}$} \\
\hline bent $D^{d}$ & $31-20$ & 51 & 104 & {$[2 \times 0] \mathrm{BS}$} \\
\hline bent $\mathrm{E}^{\mathrm{d}}$ & $26-25$ & 51 & 104 & {$[2 \times 0] \mathrm{BS}$} \\
\hline bent $E[1 \times 0]^{d}$ & $26-25$ & 51 & 103 & {$[1 \times 0]$ BS } \\
\hline bent $E[2 \times 0]^{d}$ & $26-25$ & 51 & 104 & {$[2 \times 0] \mathrm{BS}$} \\
\hline bent $E[4 \times 0]^{d}$ & $26-25$ & 51 & 106 & {$[4 \times 0] \mathrm{BS}$} \\
\hline bent $E[6 \times 0]^{d}$ & $26-25$ & 51 & 108 & {$[6 \times 0] \mathrm{BS}$} \\
\hline
\end{tabular}

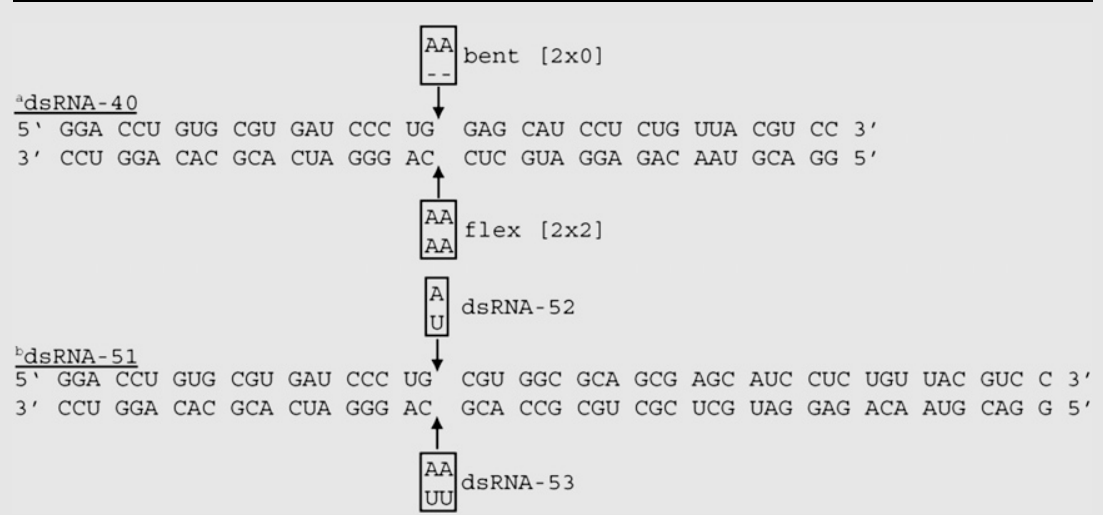

${ }^{\mathrm{c}}$ In these dsRNA chimeras, the 11 bp dsRNA central helix is replaced with an RNA:DNA hybrid, where RNA is on the top strand and DNA is on the bottom strand.

${ }^{d}$ All bulged nucleotides are A's. The dash depicts positions of A substitutions. See Figure 1 for diagram of cis and trans orientations.

${ }^{\mathrm{e}}$ " $\mathrm{s}^{\prime \prime}$ is for shortened versions of cis 1 and trans 1 ; in these, the innermost 5 bp are retained, with 3 bp deleted from either side of the central helix. 
Representative cis and trans RNAs containing two [ $2 \times 0] \mathrm{A}$ bulges in the context of a 51 base pair (bp) helix, termed "cis 2" and "trans 2," are provided in Figure 1A (Bhattacharyya et al. 1990; Zacharias and Hagerman 1995a). cis RNAs have a geometry in which 20-bp flanking helices are on the same side of a central 11-bp helix, whereas trans RNAs have these flanking helices on opposite sides of this central helix. Arms of 20 bp were chosen because PKR requires at least 16 bp for binding (Manche et al. 1992; Bevilacqua and Cech 1996), but $\geq 30$ bp for dimerization and activation (Manche et al. 1992; Zheng and Bevilacqua 2004; Lemaire et al. 2008). These lengths of flanking helices thus minimize defect-independent dimerization and activation of PKR. Eleven bp was chosen for the central region because this is the length of one turn of A-form dsRNA.

In general, the mobility of RNA on native PAGE is controlled by global geometry, with the following migration order: linear $>$ trans $>$ cis (Bhattacharyya et al. 1990). To determine if our constructs have appropriate mobilities, we compared native gel migration of dsRNA-53, trans 2 , and cis 2. As expected, these RNAs migrated in the order: dsRNA$53>$ trans $2>$ cis 2 (Fig. 1B). As all three duplexes are 106 nucleotides (nt), the observed differences in mobility can be attributed to differences in global geometry rather than mass. The addition of $\mathrm{KCl}$ to native gels did not improve resolution of these RNAs, and cis and trans duplexes containing $[1 \times 0]$

A

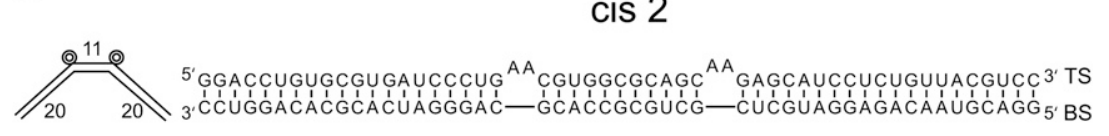

trans 2

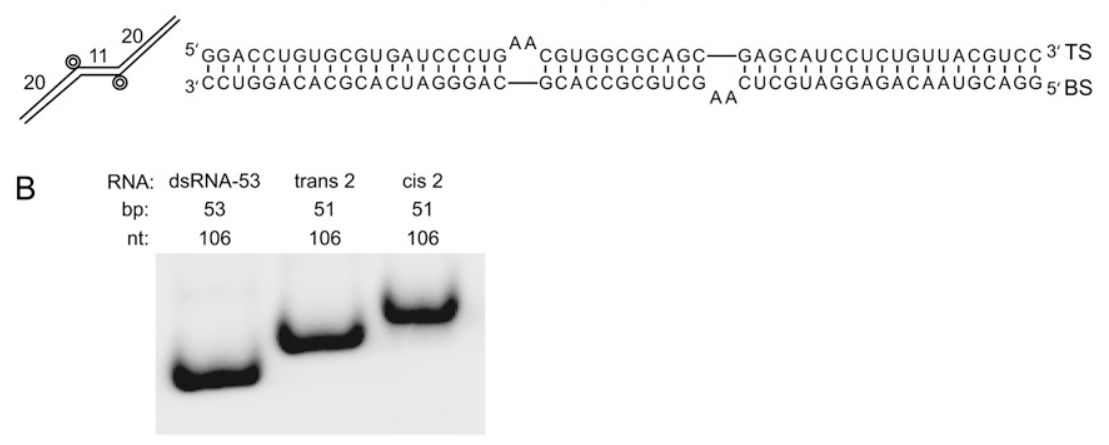

FIGURE 1. Geometry, sequence, and native gel mobility analysis of representative cis and trans RNA duplexes. (A) Global geometry and sequence of cis 2 and trans 2 duplexes. cis RNAs containing a dsRNA-51 core (shown in Table 1 footnote) were constructed with two $[2 \times 0]$ A-bulges on the top strand and a bulge-free bottom strand. trans RNAs containing a dsRNA-51 core were constructed with one $[2 \times 0]$ A-bulge on the top strand and one on the bottom strand. Nomenclature for all duplexes is detailed in Table 1. Number of A-bulges is represented by the number of concentric circles; duplex length, and bend angle in the absence of $\mathrm{Mg}^{2+}$ are drawn roughly to scale in this and other figures. $(B)$ Native PAGE mobility analysis of perfect dsRNA-53, trans 2, and cis 2 RNAs. Note that all three constructs contain $106 \mathrm{nt}$. Gel was loaded running, and RNAs were intentionally loaded from right to left, the direction of increasing mobility. Gel contains 10\% acrylamide (29:1), $0.5 \mathrm{X}$ TBE, and was run at $300 \mathrm{~V}$ and $16^{\circ} \mathrm{C}$ for $4 \mathrm{~h}$. bulges were found to have less distinct electrophoretic mobilites (data not shown).

\section{Effect of bulge position on PKR activation}

We next investigated how the position of the bulges affects activation of PKR. For these and all subsequent activation assays, two independent experiments were conducted: one representative set of gels is provided in each figure, whereas results from both experiments are shown in the quantitation, and their average provided in the text. We compared native electrophoretic mobility and PKR activation by five se-bulge containing RNAs: bent $\mathrm{A}$, bent $\mathrm{B}$, bent $\mathrm{C}$, bent , and bent E. Each RNA contains one $[2 \times 0]$ A-bulge positioned $5,10,15,20$, or $25 \mathrm{bp}$ from the end of a $51-\mathrm{bp}$ uplex (Fig. 2A). Mobility of these RNAs on native PAGE is progressively more retarded as the $[2 \times 0]$ bulge is moved ward the center of the duplex, as expected (Fig. 2B).

Next, activation assays were performed to assess differPKR phosphorylation upon changing the position of as the bulge is moved toward the center of the duplex. At $0.02-\mu \mathrm{M}$ RNA, PKR activation by bent A, bent B, bent C, , and bent $\mathrm{E}$ is, on average, 1.4-, 2.3-, 3.7-, 4.0-, and less than by dsRNA-51 RNA, respectively, while at vation is, on average, 1.5-, 1.9-, 2.1-, 2.9-, and 2.9-fold less than dsRNA-51, respectively. Thus, as the bulge is moved toward the center of the duplex there is a monotonic decrease in activation, with a substantial maximal effect of fourfold, although loss in activation can be somewhat suppressed by increasing the concentration of the RNA. Overall, an $\mathrm{A}_{2}$-bulge is a major impediment to PKR activation when presented in the proper context.

\section{Effect of bulge size on PKR activation}

Next, we examined effects of altering the size of the bulge in the context of bent E RNA, which contains a bulge in the center of the 51-bp duplex (Fig. 3). Bent E RNA had the slowest native gel mobility and was the weakest activator of PKR (Fig. 2). We compared mobility of and PKR activation by four duplexes: bent $\mathrm{E}$ $[1 \times 0]$, bent $\mathrm{E}[2 \times 0]$, bent $\mathrm{E}[4 \times 0]$, and bent $\mathrm{E}[6 \times 0]$ (Fig. $3 \mathrm{~A}$ ). Approximate bulge angles, based on the studies of Zacharias and Hagerman (1995a) are presented in Figure 3A. As expected, electrophoretic mobility on native PAGE becomes more retarded as bulge size 
A

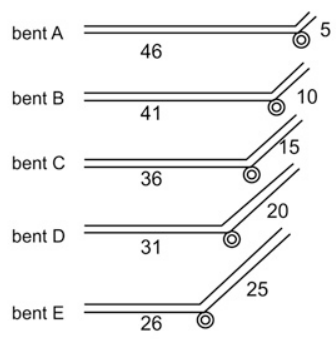

B

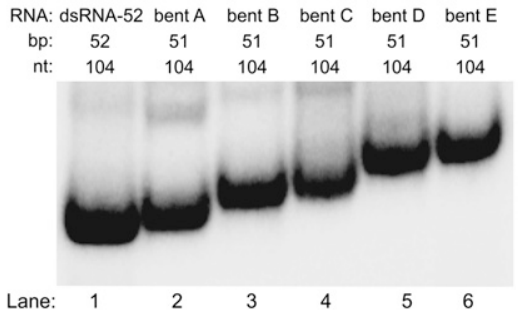

C

D
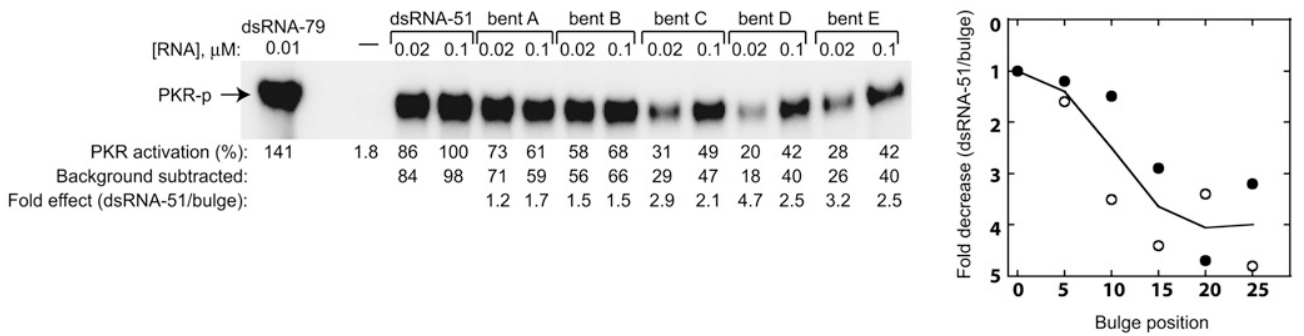

FIGURE 2. Effects of bulge position on PKR activation by bent RNAs. $(A)$ Global geometry of dsRNA-51 core bent RNAs containing one [ $2 \times 0]$ bulge located 5, 10, 15, 20, or $25 \mathrm{nt}$ from the right helical end. RNAs are named "bent A" through "bent E" (see panel; Table 1). (B) Native gel mobility analysis of perfect dsRNA-52 and the bent RNAs from panel A. Note that all constructs contain 104 nt. Gel was loaded running, and RNAs were intentionally loaded from right to left, the direction of increasing mobility. Gel contains $15 \%$ acrylamide (29:1), $0.5 \mathrm{X}$ TBE, and was run at $300 \mathrm{~V}, 16^{\circ} \mathrm{C}$ for $12 \mathrm{~h}$. (C) PKR activation by bent RNAs with different bulge positions. Representative data set provided in gel format, where percent PKR activation is normalized to dsRNA-51, and fold-effects relative to dsRNA-51 are provided. Gel is 10\% SDS-PAGE. Experiments were conducted in duplicate. $(D)$ Plot of PKR activation versus bulge position in bent RNAs for two independent data sets, depicted by filled and open symbols. RNA concentration is $0.02 \mu \mathrm{M}$. The average of these data sets is shown as the trend line.

increases, owing to a more acute bend (Fig. 3B; Lilley 1995).

An activation assay was then performed to assess differences in PKR phosphorylation upon increasing the size of the single bulge (Fig. 3C,D). Overall, activation decreases as bulge size increases. In particular, at $0.02-\mu \mathrm{M}$ RNA, PKR activation by bent $\mathrm{E}[1 \times 0],[2 \times 0],[4 \times 0]$, and $[6 \times 0]$ is, on average, 1.7-, 2.7-, 3.8-, and 7.0-fold less than dsRNA-51 RNA, respectively. Curiously, positioning flanking helices in closest proximity, as shown in bent $\mathrm{E}[6 \times 0]$ with its approximate right angle bend (Fig. $3 \mathrm{~A}$ ), only serves to further abrogate activation of PKR.

\section{Effect of bulge geometry and defect flexibility on PKR activation}

In the previous two sections, PKR activation was examined in the presence of single bulges. Next, PKR activation was tested in the presence of RNAs containing two bulges, with either cis or trans global geometry. cis and trans geometries were engineered into 45- or 51-bp RNAs with either [ $1 \times 0]$ or $[2 \times 0]$ bulges (Fig. $4 \mathrm{~A}-\mathrm{D})$. In addition, bulge defect flexibility was examined in the context of 40-bp RNAs comparing $[2 \times 0]$ and $[2 \times 2]$ defects (Supplemental Fig. S1). Three perfect duplex control RNAs were also included in these assays: dsRNA-40, dsRNA-51, and dsRNA-79. Forty bp was chosen because that is the sum of the two flanking base- paired regions in the bulged helices; 51 bp because it is the total number of base pairs in the bulged helices; and dsRNA79 because this a standard PKR control duplex.

First, we tested PKR activation by 51-bp cis and trans RNAs with $[1 \times 0]$ or $[2 \times 0]$ bulges, termed "cis 1 ," "cis 2 ," "trans 1," and "trans 2." We found that both cis and trans geometries activate PKR significantly less than either dsRNA40 or dsRNA-51 (Fig. 4A,B). Moreover, RNAs having a trans global geometry decrease PKR activation more than RNAs having a cis geometry, and increasing bulge size from 1 to $2 \mathrm{nt}$ further decreases activation in both geometries. For example, at $0.02 \mu \mathrm{M}$ RNA, activation by cis 1 , cis 2 , trans 1 , and trans 2 is, on average, 9.4-, 14-, 24-, and $>40$-fold less than dsRNA51, respectively (Fig. 4A,B,E). Similar effects hold at $0.1 \mu \mathrm{M}$ RNA (Fig. 4). When compared to the shorter dsRNA-40, overall effects were more modest in magnitude, whereas general trends were unaffected (Fig. 4). In addition, we also tested cis and trans duplexes containing [3×0] A-bulges and found them to activate PKR similarly to $[2 \times 0]$ RNAs (data not shown).

Second, we examined effects of shortening cis 1 and trans 1 RNAs from 51 to $45 \mathrm{bp}$ (Fig. 4C). The shortened duplexes, termed "cis 1s" and "trans 1s," have a 5-bp central helix and 20-bp flanking helices (Table 1). Our hypothesis was that by shortening the central double helical segment, which moves the two 20-bp ends closer together, we might restore activation. (Due to the presence of just a half-turn of dsRNA 
A

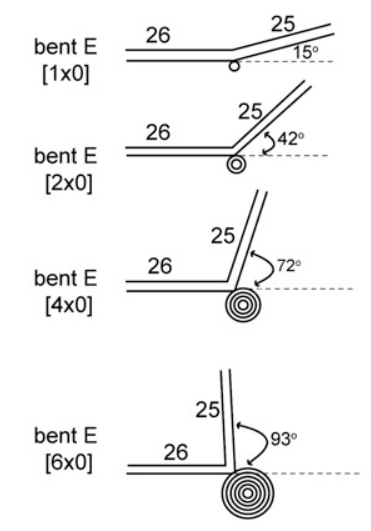

B

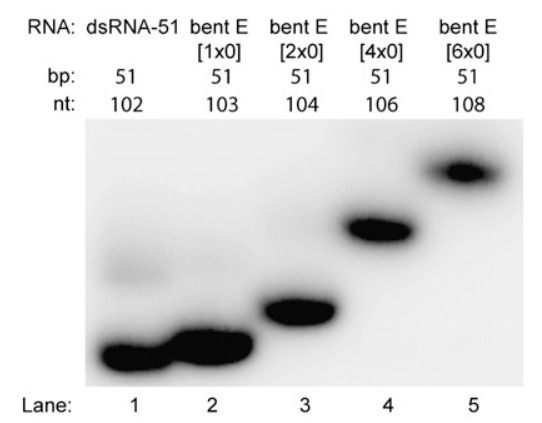

C

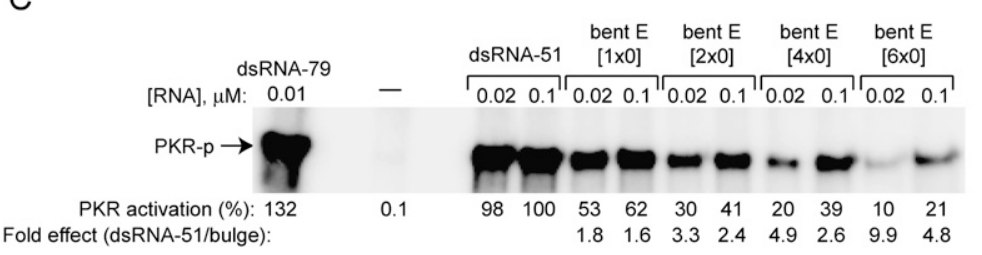

D

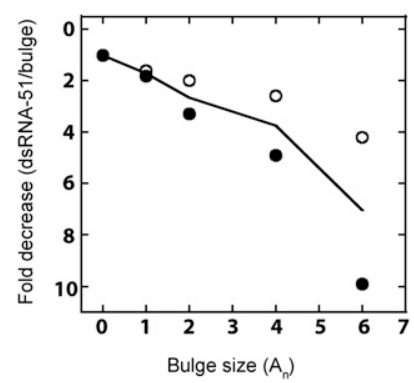

FIGURE 3. Effect of bulge size on PKR activation. $(A)$ Global geometry of bent E RNAs containing one $[1 \times 0],[2 \times 0],[4 \times 0]$, and $[6 \times 0]$ A-bulge. Approximate bulge angles, based on the studies of Zacharias and Hagerman (1995a) are provided. (B) Native gel mobility analysis of bent E RNAs. Gel was loaded running and RNAs were intentionally loaded from right to left, the direction of increasing mobility. Gel contains $15 \%$ acrylamide (29:1), 0.5X TBE, and was run at $300 \mathrm{~V}, 16^{\circ} \mathrm{C}$ for $8 \mathrm{~h}$. (C) PKR activation by bent E RNAs with different bulge sizes. Representative data set is provided in gel format, where percent PKR activation is normalized to dsRNA-51, and fold-effects relative to dsRNA-51 are provided. Gel is 10\% SDS-PAGE. Experiments were conducted in duplicate. (D) Plot of PKR activation versus A-bulge size for two independent data sets, depicted by filled and open symbols. RNA concentration is at $0.02 \mu \mathrm{M}$. The average of these data sets is shown as the trend line.

in the central helix, helices were engineered with bulges positioned on strands opposite those shown in Figure 1A for 51-bp cis and trans duplexes-see Table 1.) PKR was significantly less activated by the shortened central helices for the cis constructs (Fig. 4C). Thus, contrary to our expectations, shortening cis RNAs significantly decreased activation. Shortening trans RNAs appears to have an effect on activation as well, however these effects are more difficult to assess because trans RNAs are poorer activators to begin with. Apparently, PKR activation is enhanced when the multiple defects in a helix are spaced further apart.

Next, we considered whether PKR monomers in an active complex overlap the bulges, or act through space. To test this, we constructed chimeric forms of dsRNA-51 (dsRNA-51-chi) and cis 2 (cis 2-chi) in which the central 11-bp RNA portion was replaced by an RNA/DNA hybrid (Fig. 4D), which does not support dsRBM binding (Bevilacqua and Cech 1996). Activation of PKR by dsRNA-51-chi decreased, on average, by 35 -fold compared to dsRNA-51 at a $0.02-\mu \mathrm{M}$ RNA. Moreover, activation of PKR by cis 2-chi was considerably weaker than by cis 2 . These data suggest that in either perfect or bent dsRNA, activation of PKR does not occur through space, and that PKR instead has to overlap these defects (see Discussion).
Effect of incorporating a flexible $[2 \times 2]$ symmetric internal loop in a 40-bp RNA, termed "flex [2 $\times 2$ ]," on activation of PKR was also tested (Supplemental Fig. S1). We reasoned that if we provided bases opposing the bulged bases, which remove bending (Riordan et al. 1992), stronger activation might be restored; as noted earlier, internal loops are points of flexibility (Kahn et al. 1994). As with cis and trans RNAs, we retained short (20-bp) terminal helices to discourage binding of more than one PKR molecule per helix terminus. To provide comparison of the effect of an internal loop on PKR activation, we included in the assay both dsRNA-40 and a 40-bp bulged RNA termed "bent $[2 \times$ 0]." At a $0.02-\mu \mathrm{M}$ RNA, PKR activation by bent $[2 \times 0]$ and flex $[2 \times 2]$ are 3.8- and 5.7-fold less than dsRNA-40, respectively (Supplemental Fig. S1). Thus, incorporating a flexible internal loop disfavors PKR activation and has a larger effect than an asymmetric bulge.

We conducted native gel mobility shift assays of PKR's dsRBD (P20) with five RNAs: dsRNA-51, dsRNA-51-chi, cis 2, cis 2-chi, and trans 2 RNAs (Supplemental Fig. S2). No appreciable differences in binding were observed among these. All RNAs gave 5-7 band shifts, as one would expect based on length of these duplexes (Manche et al. 1992), and 
A

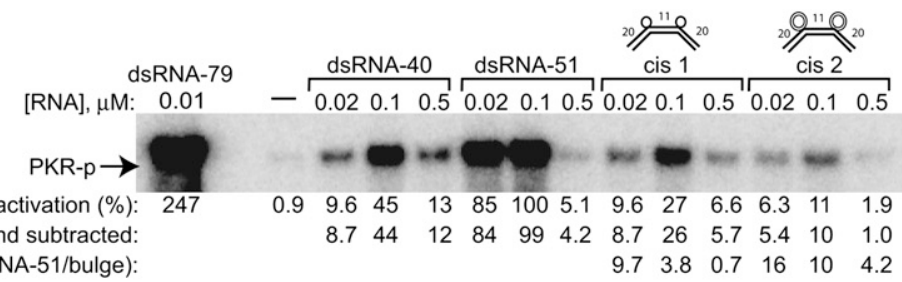

B

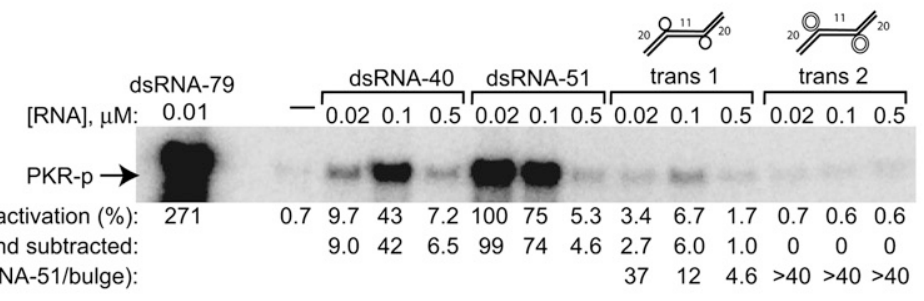
Fold effect (dsRNA-51/bulge):
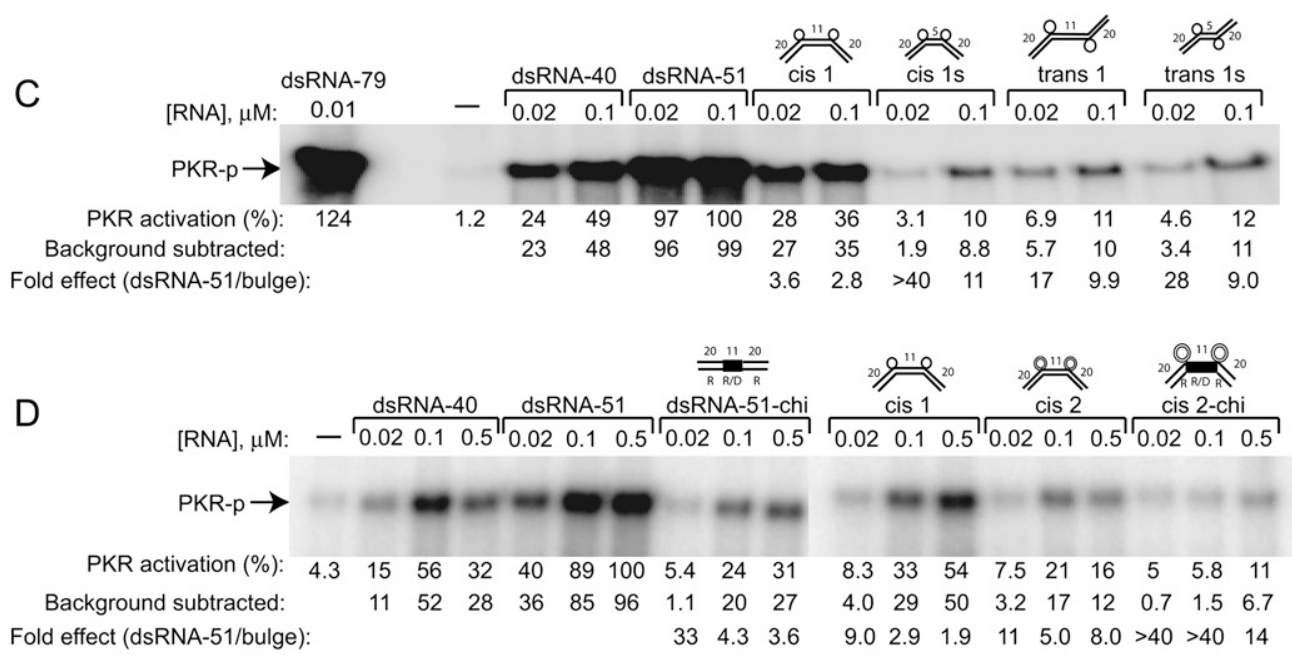

$\mathrm{E}$

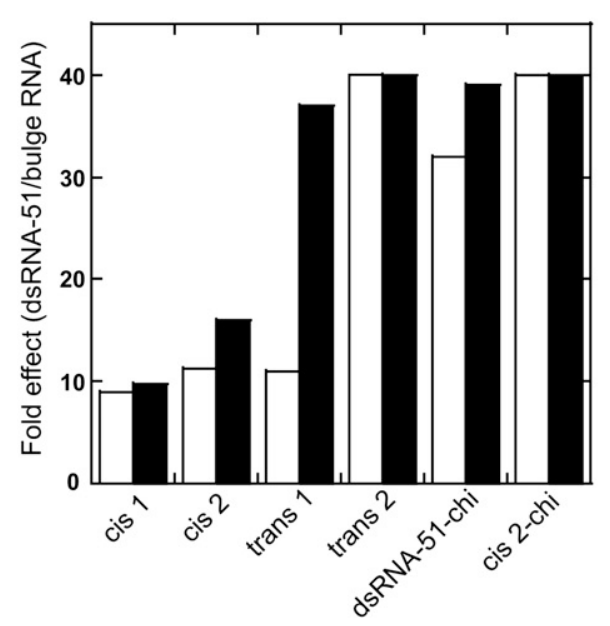

FIGURE 4. Effect of bulge geometry on PKR activation. (A) PKR activation by cis and (B) trans RNAs, both based on the dsRNA-51 core. Gels are $10 \%$ SDS-PAGE. $(C)$ PKR activation by cis and trans RNAs containing two $[1 \times 0]$ bulges separated by different spacers, either 11 or 5 bp. $(D)$ PKR activation by chimeric duplexes, 51-bp chi and cis 2-chi, compared to all-RNA duplexes. Chimeric region depicted by filled lines. (E) Foldeffects of bulge RNAs compared to dsRNA-51 at $0.02 \mu \mathrm{M}$ concentration of duplex, in which fold-effects from two independent data sets are shown by filled and open bars. In all gel panels, percent PKR activation is normalized to dsRNA-51, and fold-effects relative to dsRNA-51 are provided. Reactions were stopped at $10 \mathrm{~min}$ except panel $C$, which was stopped at $20 \mathrm{~min}$. Gels are 10\% SDS-PAGE. 
for all RNAs the concentration of P20 required to completely shift the free RNA was nearly the same. This behavior is generally consistent with our previous work on modified dsRNAs, wherein nonactivating modified RNAs gave similar binding activity as activating unmodified RNAs (Nallagatla and Bevilacqua 2008). Overall, binding and activation of PKR by the RNAs herein is not equivalent, and we conclude that orientation of PKR on the dsRNA is also of critical importance for activation (see Discussion).

Lastly, we point out that it remains possible that small and difficult to detect differences in binding are incurred due to the presence of the chimeric stretch; such differences have the potential to be quite significant for PKR activation due to orientational and positioning effects, but can be subtle to detect by a binding assay due to the many registers for P20 binding. Further studies, including high-resolution structures, will be needed to resolve such issues.

\section{Effect ionic strength on the kinetics of PKR activation}

Ionic strength affects the flexibility of helical DNA, with greater ionic strength leading to more flexibility (Kam et al. 1981). In an effort to gain insight into how helical flexibility might affect PKR activation, we investigated the effects of lowering salt concentration from the standard value of 100 to $50 \mathrm{mM}$ on the kinetics of PKR activation in the presence of a few RNAs: dsRNA-51, cis 2, trans 2, and bent D RNAs. Four time points $(4,10,30$, and $60 \mathrm{~min})$ were collected for activation assays in the presence of 50 or $100 \mathrm{mM} \mathrm{KCl}$, and normalized percent activation assays were plotted (plots in Fig. 5 and gels in Supplemental Fig. S3).

PKR activation assays were first performed in $50 \mathrm{mM} \mathrm{KCl}$, which is below biological ionic strength, and revealed only small differences between the three $[2 \times 0]$ duplexes relative to dsRNA-51, with cis 2 and bent $\mathrm{D}$ being slightly better activators than trans 2 (Fig. 5, open symbols). For instance, at 10 min and an RNA concentration of $0.02 \mu \mathrm{M}$, cis 2 , trans 2 ,
A

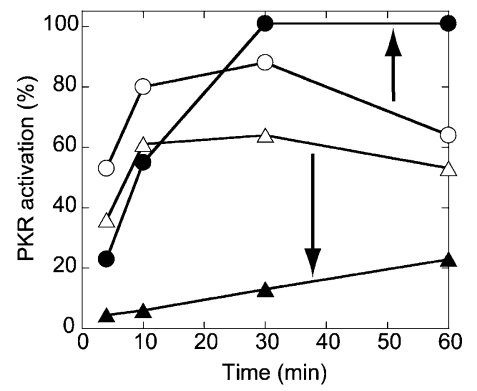

B

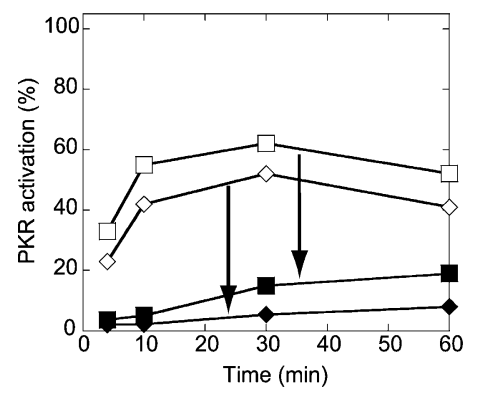

FIGURE 5. Effect of ionic strength and time on PKR activation by various helical defects. Time points were collected at 4, 10,30, and $60 \mathrm{~min}$. Different ionic strengths are shown with open $(50 \mathrm{mM} \mathrm{KCl})$ or filled $(100 \mathrm{mM} \mathrm{KCl})$ symbols. (A) Plot of PKR activation versus time for $0.02-\mu \mathrm{M}$ dsRNA-51 $(\bigcirc, \boldsymbol{O})$ and bent $\mathrm{D}(\triangle, \mathbf{\Delta})$. (B) Plot of PKR activation versus time for $0.02-\mu \mathrm{M}$ cis $2(\square, \boldsymbol{\square})$ and trans $2(\diamond, \diamond)$. Percent PKR activation is normalized to $0.01-\mu \mathrm{M}$ dsRNA-79 RNA. Arrows depict the effect of increasing ionic strength. Gels are provided in Supplemental Fig. S3. and bent $\mathrm{D}$ were reduced in activity relative to dsRNA- 51 by only 1.5-, 1.9-, and 1.3-fold, respectively (Supplemental Fig. S3A). Moreover, initial rates of phosphorylation were similar for all RNAs, with bulged RNAs differing from perfect dsRNA by just 1.5- to 2.3 -fold (Table 2).

Next, we considered time courses of PKR activation assays in a higher and more biologically relevant (Alberts et al. 1994) concentration of $\mathrm{KCl}$. Remarkably, assays in $100 \mathrm{mM} \mathrm{KCl}$ revealed a much greater loss in activity for the three bulgecontaining duplexes than perfect dsRNA-51 (Fig. 5, closed symbols). For example, at $10 \mathrm{~min}$ and an RNA concentration of $0.02 \mu \mathrm{M}$, cis 2 , trans 2 , and bent $\mathrm{D}$ were reduced in activity relative to dsRNA-51 by 11-, >20-, and 9.2-fold, respectively (Supplemental Fig. S3B). Moreover, the time dependence for PKR activation revealed that dsRNA-51 reaches a plateau at $30 \mathrm{~min}$, but that cis 2, trans 2, and bent D RNAs are still increasing in phosphorylation even at $1 \mathrm{~h}$ (Fig. 5, closed symbols). Also, initial rates for bulged RNAs were lower by a striking $\sim 30-60$-fold in $100 \mathrm{mM} \mathrm{KCl}$ (Table 2).

Last, ionic strength altered the shape of the activation profiles somewhat. In particular, activation profiles for bent $\mathrm{D}$, cis 2 , and trans 2 at higher ionic strength reveal the optimal RNA concentrations for activation shifted from 0.02 to 0.1 $\mu \mathrm{M}$ (Supplemental Fig. S3). In sum, a biologically relevant ionic strength disfavors activation of PKR by defect-containing RNAs in two ways: more RNA is required for activation, and the kinetics of activation are much slower.

\section{DISCUSSION}

The protein kinase PKR acts in the innate immunity pathway by sensing RNA (Robertson and Mathews 1996; Williams 1999; Nallagatla et al. 2008). However, the features of RNA that lead to activation have not been fully established. In this study, we tested effects of RNA defect position, size, and geometry on activation of PKR. All bulges examined led to decreased activation of PKR relative to perfect dsRNA, with the largest suppression observed for RNAs with centrally positioned bulges, large bulges, and multiple bulges in a trans geometry. In addition, activation by bulged RNAs was suppressed by increasing ionic strength to a biologically relevant concentration.

Overall, the dependence of activation on bulge position has a sigmoidal shape (Fig. 2D). Loss in PKR activation with bulge position is steepest in bent $\mathrm{C}$, which has the bulge $15 \mathrm{bp}$ from the end of $51 \mathrm{bp}$, with only minor further losses in activation in going to bent $\mathrm{D}(20 \mathrm{bp}$ from end) and bent $\mathrm{E}$ ( $25 \mathrm{bp}$ from end) (Fig. 2C,D). Notably, bent $\mathrm{C}$ has a bulgefree segment of just $36 \mathrm{bp}$, which is similar to the minimal length needed 
TABLE 2. Ionic strength dependence of initial rates of PKR phosphorylation

\begin{tabular}{lccc}
\hline RNA construct & $\begin{array}{c}\text { Slope } \\
(\% \text { activation/min }) \\
50 \mathrm{mM} \mathrm{KCl}\end{array}$ & $\begin{array}{c}\text { Slope } \\
(\% \text { activation/min }) \\
100 \mathrm{mM} \mathrm{KCl}^{\mathrm{b}}\end{array}$ & $\begin{array}{c}\text { Fold-effect of } \\
\text { ionic strength } \\
(50 \mathrm{mM} / 100 \mathrm{mM} \mathrm{KCl})\end{array}$ \\
\hline dsRNA-51 & 13.3 & 5.3 & 2.5 \\
bent D & 9.0 & 0.3 & 30 \\
cis 2 & 8.3 & 0.3 & 28 \\
trans 2 & 5.8 & 0.1 & 58 \\
\hline
\end{tabular}

Results are from linear fits to data plotted in Figure 5.

a Initial rates were determined using only the first time point for all RNAs.

b Initial rates were determined using the first two time points for dsRNA-51, and all four time points for bent $\mathrm{D}$, cis 2 , and trans 2 .

for dimerization (Lemaire et al. 2008) and to the activating length of $\sim 33$ bp (Manche et al. 1992; Zheng and Bevilacqua 2004). These data strongly suggest that bent A (5 bp from end) and bent $B$ (10 bp end) use their longer bulge-free segments (of 46 and $41 \mathrm{bp}$ ) to activate PKR. Thus, an $\mathrm{A}_{2}$-bulge is a major impediment to PKR activation when presented in a central context.

Recalling that PKR requires a minimum of $16 \mathrm{bp}$ to bind (Bevilacqua and Cech 1996), we might expect bent B and dsRNA-40 to activate to the same extent. However, at $0.02 \mu \mathrm{M}$ RNA activation is sixfold higher for bent $\mathrm{B}$ than dsRNA-40 (Figs. 2C, 4A,B). Thus, short helices flanking an optimal activation helix appear to augment activation. One possibility is that PKR is capable of binding across bulges in a manner that enhances activation relative to dsRNA-40, albeit not to the same extent as a perfect 51 bp helix (Fig. 2C,D) (see model in the following).

Increasing the size of the bulge from $[1 \times 0]$ to $[6 \times 0]$ progressively decreased activation of PKR. Presumably this arises because increasing the bend angle in the RNA from $15^{\circ}$ to $93^{\circ}$ (Zacharias and Hagerman 1995b) disfavors productive dimerization of PKR. These observations further suggest that the two monomers of PKR in an activation complex do not interact through space, otherwise increasing the bend angle should drive association of PKR monomers (see model in the following).

A minimal model for activation of PKR by bulged RNAs is presented in Figure 6. Three panels are provided, each with the same final state for activation, on the basis of results provided herein and parsimony. Panel A presents the standard model for PKR dimerization and activation on perfect dsRNA, which is supported by a wealth of biophysical data (Lemaire et al. 2005; Cole 2007). Panel B presents a model for PKR dimerization and activation on cis 2 RNA, which is quite similar to the model in panel A involving PKR dimerization, as supported by bell-shaped activation profiles (Fig. 4). Straightening, diagrammed in this panel, is supported by independent studies (Zheng and Bevilacqua 2000). Weaker activation of PKR by this RNA as compared to perfect dsRNA, as observed in Figure 4, may be due in part to the thermodynamic penalty for binding to bent RNAs (Zheng and Bevilacqua 2000), although further biophysical studies are needed to confirm this. Panel C presents a model for PKR dimerization and activation by cis 2chi RNAs, which is also quite similar to panel A involving PKR dimerization. The weakest activation by this RNA, as observed in Figure 4, can be understood by the double penalty of PKR having to bind to bent RNA and having to contend with an RNA-DNA hybrid, for which PKR has poor affinity (Bevilacqua and Cech 1996; Zheng and Bevilacqua 2000). PKR having to contend with this RNADNA hybrid region rejects through-space interaction of PKR monomers.

To address the observation that cis is a better activator than trans, it is reasonable to suggest that PKR monomers prefer to bind just one face of dsRNA, which is bulge-free in the cis (but not the trans) geometry. Observation of lesser activation by closely spaced defects further indicates importance of PKR monomer orientation. Additional experiments, including high-resolution structures, are needed to fully develop models consistent with these particular details.

Last, bulged RNAs had a large negative dependence on ionic strength, whereas perfect dsRNAs did not (Fig. 5). Reduced flexibility (i.e., increased persistence length) of nucleic acids has been reported in lower ionic strength (Hagerman 1981; Kam et al. 1981). Thus, helix stiffening might cause the various defect-containing RNA substrates to interact more productively with PKR in lower ionic strength. Likewise, gain in flexibility in $100 \mathrm{mM} \mathrm{KCl}$ supports a larger population of bent RNA states, which appears to be less compatible with PKR activation (Zheng and Bevilacqua 2000). Consistent with this notion, an RNA containing a flexible [ $2 \times 2]$ internal loop was a poor activator of PKR (Supplemental Fig. S1).

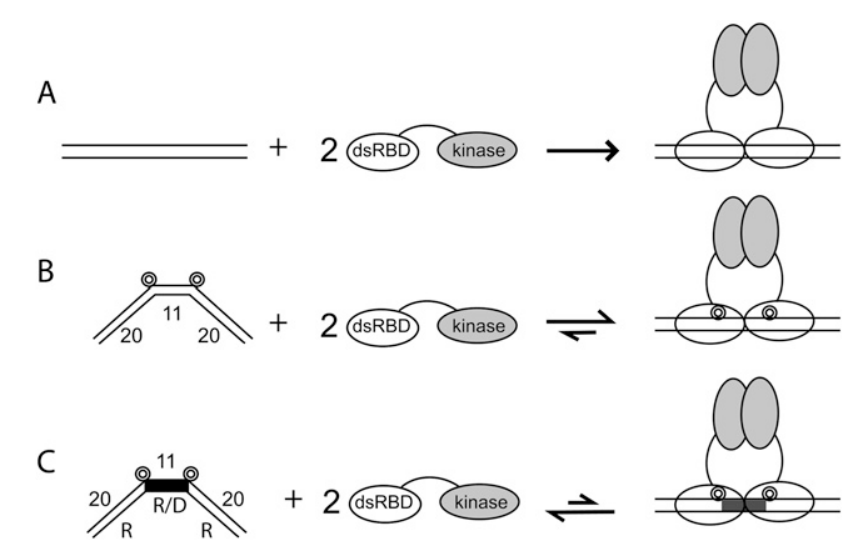

FIGURE 6. Model for PKR dimerization and activation on bulgecontaining RNAs. Activation by $(A)$ perfect dsRNA; $(B)$ cis 2 dsRNA; and $(C)$ cis 2-chi dsRNA. Positions of equilibrium are denoted with various arrowheads. 
As $100 \mathrm{mM} \mathrm{KCl}$ is similar to, or still slightly lower than, physiological ionic strength $(140 \mathrm{mM} \mathrm{KCl})$ (Alberts et al. 1994), these data suggest that the ability of PKR to discriminate between various biological RNA substrates is enhanced under physiological salt conditions, although additional physiological parameters, such as macromolecular crowding, remain to be explored. Importantly, the results herein also suggest that such poorer activation by bulged RNAs under physiological conditions can still be overcome by increasing the concentration of RNA, which certain viruses appear to do (Schneider et al. 1985; O’Malley et al. 1986).

\section{MATERIALS AND METHODS}

\section{Protein expression and purification}

Full-length PKR, containing an N-terminal (His) 6 , was cloned into pET-28a (Novagen, Inc.) and transformed into Escherichia coli BL21 (DE3) Rosetta cells (Novagen, Inc.), as previously described (Bevilacqua and Cech 1996; Zheng and Bevilacqua 2004; Nallagatla et al. 2007). Briefly, cells were sonicated and the protein was purified by a $\mathrm{Ni}^{2+}$-agarose column (Qiagen, Inc.). PKR was dialyzed into storage buffer: $10 \mathrm{mM}$ Tris ( $\mathrm{pH} 7.6$ ), $50 \mathrm{mM} \mathrm{KCl}, 2 \mathrm{mM} \mathrm{MgOAc}$, $10 \%$ glycerol, and $7 \mathrm{mM} \beta$-mercaptoethanol. Isolated protein was treated with $\lambda$-PPase (NEB) before PKR activation assays as described below.

\section{RNA preparation and purification}

RNAs were prepared by transcription from a hemiduplex template by T7 RNA polymerase (Milligan and Uhlenbeck 1989), except for dsRNA-79, which was prepared from pUC19 as previously described (Zheng and Bevilacqua 2004). Chimeric bottom strand RNAs were purchased from Dharmacon. The sequences of relevant RNA duplexes are found in the figures and at the end of Table 1. All RNAs were purified by denaturing 8\% PAGE, and the band corresponding to full-length transcript was excised and soaked overnight at $4^{\circ} \mathrm{C}$ in $1 \mathrm{X} \mathrm{TEN}{ }_{250}$ (10 mM Tris [pH 7.5], 1 mM EDTA, $250 \mathrm{mM} \mathrm{NaCl}$ ). Subsequently, RNAs were ethanol precipitated and resuspended in $1 \mathrm{X}$ TE (10 $\mathrm{mM}$ Tris [pH 7.5], $1 \mathrm{mM}$ EDTA). Concentrations of RNAs were determined spectrophotometrically. 5 '-end labeled RNAs were prepared by first treating with calf intestinal phosphatase, followed by polynucleotide kinase treatment in the presence of $\left[\gamma^{32} \mathrm{P}\right] \mathrm{ATP}$.

\section{Native gel mobility analysis}

Native gels containing 10\% or 15\% of 29:1 (acrylamide: bis) crosslinking polyacrylamide were used to analyze the mobility differences between various bulged duplex RNAs. The buffer in both the gel and running electrophoresis was $0.5 \mathrm{X}$ TBE ( $50 \mathrm{mM}$ Tris base, $40 \mathrm{mM}$ boric acid, $0.5 \mathrm{mM}$ EDTA). Native gels were run between 4 and $12 \mathrm{~h}$ at $300 \mathrm{~V}$ and $16^{\circ} \mathrm{C}$.

Prior to loading onto a native gel, trace amounts $(\sim 1 \mathrm{nM})$ of 5 '-end labeled top strand RNA was added to $10 \mu \mathrm{M}$ unlabeled top and $11 \mu \mathrm{M}$ unlabeled bottom strand RNA and renatured in $1 \mathrm{X}$ TEK $_{100}(10 \mathrm{mM}$ Tris [pH 7.5], $1 \mathrm{mM}$ EDTA, $100 \mathrm{mM} \mathrm{KCl}$ ) by heating at $90^{\circ} \mathrm{C}$ for $3 \mathrm{~min}$. This sample was then incubated at room temperature for $10 \mathrm{~min}$. Gels were exposed to a storage screen and analyzed on a PhosphorImager (Molecular Dynamics).

Binding of dsRBD (P20) to perfect dsRNAs and bulge containing dsRNAs were carried out by native gel mobility shift assays as previously described (Bevilacqua and Cech 1996). Duplex RNAs were prepared as previously described, except unlabeled top and bottom strand RNA concentrations were 2 and $3 \mu \mathrm{M}$, respectively. Samples were prepared in binding buffer (BB: $25 \mathrm{mM}$ Hepes [pH 7.5], $10 \mathrm{mM} \mathrm{NaCl}$, $5 \%$ glycerol, $5 \mathrm{mM} \mathrm{DTT}, 0.1 \mathrm{mM} \mathrm{EDTA}, 0.1 \mathrm{mg} / \mathrm{mL}$ tRNA [Sigma]). In the binding reactions, RNA was kept at a limiting concentration $(0.01 \mathrm{nM})$. Binding reactions were loaded onto a running $10 \%$ (29:1 acrylamide/bis) native gel. The gel and the running buffer contained $0.5 \mathrm{X} \mathrm{TBE}$ and the electrophoresis was performed at $300 \mathrm{~V}$, at $16^{\circ} \mathrm{C}$ for $2 \mathrm{~h}$. All binding assays were conducted at least two times.

\section{PKR activation assays}

RNAs were tested for their ability to activate PKR. Prior to activation assays, PKR was dephosphorylated by $\lambda$-PPase (NEB) for 1 $\mathrm{h}$ at $30^{\circ} \mathrm{C}$, and then inhibited with $2 \mathrm{mM}$ sodium orthovanadate. The $\lambda$-PPase-treated PKR $(0.6 \mu \mathrm{M})$ was incubated with various concentrations of RNA in $20 \mathrm{mM}$ HEPES (pH 7.5), $4 \mathrm{mM} \mathrm{MgCl}_{2}$, $100 \mathrm{mM} \mathrm{KCl}, 1.5 \mathrm{mM}$ DTT, $100 \mu \mathrm{M}$ ATP (Ambion), and $15 \mu \mathrm{Ci}$ $\left[\gamma^{-}{ }^{32} \mathrm{P}\right]$-ATP. RNA duplexes were renatured at $10 \mu \mathrm{M}$ concentrations at $90^{\circ} \mathrm{C}$ for $3 \mathrm{~min}$, incubated at room temperature for $10 \mathrm{~min}$, and then serially diluted. Reaction mixtures were incubated at $30^{\circ} \mathrm{C}$ between 4 and $60 \mathrm{~min}$, quenched with SDS stop buffer, and PKR phosphorylation was analyzed on $10 \%$ SDS-PAGE gels (Pierce). Gels were exposed to a storage PhosphorImager screen, and intensities of PKR bands were quantified using a PhosphorImager (Molecular Dynamics). In activation assay gels, a no-RNA lane is provided, and phosphorylation activities are normalized to perfect duplexes dsRNA-40, dsRNA-51, or dsRNA-79. PKR activation assays were conducted at least two times.

\section{SUPPLEMENTAL MATERIAL}

Supplemental material is available for this article.

\section{ACKNOWLEDGMENTS}

This work was supported by National Institutes of Health grant no. GM-58709 (to P.C.B.).

Received January 20, 2011; accepted February 24, 2011.

\section{REFERENCES}

Alberts B, Bray D, Lewis J, Raff M, Roberts K, Watson JD. 1994. Molecular biology of the cell. Garland, New York.

Ben-Asouli Y, Banai Y, Pel-Or Y, Shir A, Kaempfer R. 2002. Human interferon-gamma mRNA autoregulates its translation through a pseudoknot that activates the interferon-inducible protein kinase PKR. Cell 108: 221-232.

Bevilacqua PC, Cech TR. 1996. Minor-groove recognition of doublestranded RNA by the double-stranded RNA-binding domain from the RNA-activated protein kinase PKR. Biochemistry 35: 99839994.

Bevilacqua PC, George CX, Samuel CE, Cech TR. 1998. Binding of the protein kinase PKR to RNAs with secondary structure defects: role 
of the tandem A-G mismatch and noncontiguous helixes. Biochemistry 37: 6303-6316.

Bhattacharyya A, Murchie AIH, Lilley DMJ. 1990. RNA bulges and the helical periodicity of double-stranded RNA. Nature 343: 484487.

Cohen-Chalamish S, Hasson A, Weinberg D, Namer LS, Banai Y, Osman F, Kaempfer R. 2009. Dynamic refolding of IFN-gamma mRNA enables it to function as PKR activator and translation template. Nat Chem Biol 5: 896-903.

Cole JL. 2007. Activation of PKR: an open and shut case? Trends Biochem Sci 32: 57-62.

Garcia MA, Gil J, Ventoso I, Guerra S, Domingo E, Rivas C, Esteban M. 2006. Impact of protein kinase PKR in cell biology: from antiviral to antiproliferative action. Microbiol Mol Biol Rev 70: 1032-1060.

Hagerman PJ. 1981. Investigation of the flexibility of DNA using transient electric birefringence. Biopolymers 20: 1503-1535.

Heinicke LA, Wong CJ, Lary J, Nallagatla SR, Diegelman-Parente A, Zheng X, Cole JL, Bevilacqua PC. 2009. RNA dimerization promotes PKR dimerization and activation. J Mol Biol 390: 319338.

Hsieh CH, Griffith JD. 1989. Deletions of bases in one strand of duplex DNA, in contrast to single-base mismatches, produce highly kinked molecules: possible relevance to the folding of single-stranded nucleic acids. Proc Natl Acad Sci 86: 4833-4837.

Jacquemont B, Roizman B. 1975. RNA synthesis in cells infected with herpes simplex virus. X. Properties of viral symmetric transcripts and of double-stranded RNA prepared from them. J Virol 15: 707713.

Kahn JD, Yun E, Crothers DM. 1994. Detection of localized DNA flexibility. Nature 368: 163-166.

Kam Z, Borochov N, Eisenberg H. 1981. Dependence of laser light scattering of DNA on $\mathrm{NaCl}$ concentration. Biopolymers 20: 26712690.

Katze MG, DeCorato D, Safer B, Galabru J, Hovanessian AG. 1987. Adenovirus VAI RNA complexes with the $68,000 M_{r}$ protein kinase to regulate its autophosphorylation and activity. EMBO J 6: 689-697.

Kebbekus P, Draper DE, Hagerman P. 1995. Persistence length of RNA. Biochemistry 34: 4354-4357.

Lemaire PA, Lary J, Cole JL. 2005. Mechanism of PKR activation: dimerization and kinase activation in the absence of doublestranded RNA. J Mol Biol 345: 81-90.

Lemaire PA, Anderson E, Lary J, Cole JL. 2008. Mechanism of PKR activation by dsRNA. J Mol Biol 381: 351-360.

Lilley DMJ. 1995. Kinking of DNA and RNA by base bulges. Proc Natl Acad Sci 92: 7140-7142.

Lu Y, Weers B, Stellwagen NC. 2001. DNA persistence length revisited. Biopolymers 61: 261-275.

Manche L, Green SR, Schmedt C, Mathews MB. 1992. Interactions between double-stranded RNA regulators and the protein kinase DAI. Mol Cell Biol 12: 5238-5248.

Maran A, Mathews MB. 1988. Characterization of the doublestranded RNA implicated in the inhibition of protein synthesis in cells infected with a mutant adenovirus defective for VA RNA. Virology 164: 106-113.

Milligan JF, Uhlenbeck OC. 1989. Synthesis of small RNAs using T7 RNA polymerase. Methods Enzymol 180: 51-62.

Nallagatla SR, Bevilacqua PC. 2008. Nucleoside modifications modulate activation of the protein kinase PKR in an RNA structurespecific manner. RNA 14: 1201-1213.

Nallagatla SR, Hwang J, Toroney R, Zheng X, Cameron CE, Bevilacqua PC. 2007. 5'-Triphosphate-dependent activation of PKR by RNAs with short stem-loops. Science 318: 1455-1458.

Nallagatla SR, Toroney R, Bevilacqua PC. 2008. A brilliant disguise for self RNA: $5^{\prime}$-end and internal modifications of primary transcripts suppress elements of innate immunity. RNA Biol 5: 25-29.

O’Malley RP, Mariano TM, Siekierka J, Mathews MB. 1986. A mechanism for the control of protein synthesis by adenovirus VA RNA . Cell 44: 391-400.

Rice JA, Crothers DM. 1989. DNA bending by the bulge defect. Biochemistry 28: 4512-4516.

Riordan FA, Bhattacharyya A, McAteer S, Lilley DM. 1992. Kinking of RNA helices by bulged bases, and the structure of the human immunodeficiency virus transactivator response element. $J \mathrm{Mol}$ Biol 226: 305-310.

Robertson HD, Mathews MB. 1996. The regulation of the protein kinase PKR by RNA. Biochimie 78: 909-914.

Schneider RJ, Safer B, Munemitsu SM, Samuel CE, Shenk T. 1985. Adenovirus VAI RNA prevents phosphorylation of the eukaryotic initiation factor $2 \alpha$ subunit subsequent to infection. Proc Natl Acad Sci 82: 4321-4325.

Tang RS, Draper DE. 1990. Bulge loops used to measure the helical twist of RNA in solution. Biochemistry 29: 5232-5237.

Tang RS, Draper DE. 1994. On the use of phasing experiments to measure helical repeat and bulge loop-associated twist in RNA. Nucleic Acids Res 22: 835-841.

Wang YH, Griffith J. 1991. Effects of bulge composition and flanking sequence on the kinking of DNA by bulged bases. Biochemistry 30: 1358-1363.

Wang YH, Howard MT, Griffith JD. 1991. Phased adenine tracts in double-stranded RNA do not induce sequence-directed bending. Biochemistry 30: 5443-5449.

Williams BR. 1999. PKR; a sentinel kinase for cellular stress. Oncogene 18: $6112-6120$.

Zacharias M, Hagerman PJ. 1995a. Bulge-induced bends in RNA: quantification by transient electric birefringence. J Mol Biol 247: 486-500.

Zacharias M, Hagerman PJ. 1995b. The bend in RNA created by the trans-activation response element bulge of human immunodeficiency virus is straightened by arginine and by Tat-derived peptide. Proc Natl Acad Sci 92: 6052-6056.

Zheng X, Bevilacqua PC. 2000. Straightening of bulged RNA by the double-stranded RNA-binding domain from the protein kinase PKR. Proc Natl Acad Sci 97: 14162-14167.

Zheng X, Bevilacqua PC. 2004. Activation of the protein kinase PKR by short double-stranded RNAs with single-stranded tails. RNA 10: 1934-1945. 

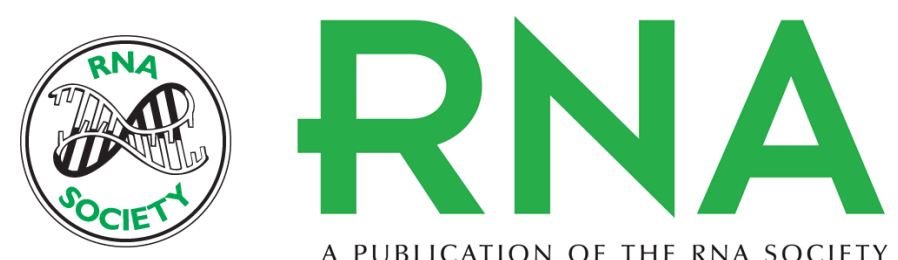

A PUBLICATION OF THE RNA SOCIETY

\section{RNA helical imperfections regulate activation of the protein kinase PKR: Effects of bulge position, size, and geometry}

Laurie A. Heinicke, Subba Rao Nallagatla, Chelsea M. Hull, et al.

RNA 2011 17: 957-966 originally published online April 1, 2011

Access the most recent version at doi:10.1261/rna.2636911

\section{Supplemental http://rnajournal.cshlp.org/content/suppl/2011/03/11/rna.2636911.DC1 \\ Material}

References This article cites 39 articles, 11 of which can be accessed free at:

http://rnajournal.cshlp.org/content/17/5/957.full.html\#ref-list-1

\section{License}

Email Alerting Receive free email alerts when new articles cite this article - sign up in the box at the Service top right corner of the article or click here.

\section{IIIII!' Providing Precise Solutions for your research.}

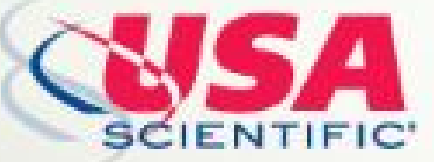

To subscribe to $R N A$ go to:

http://rnajournal.cshlp.org/subscriptions 